\title{
Fabry disease in children: a federal screening programme in Russia
}

\author{
Leyla Seymurovna Namazova-Baranova ${ }^{1}$ Alexander Alexandrovich Baranov ${ }^{1}$. \\ Aleksander Alekseevich Pushkov ${ }^{2}$ Kirill Victorovich Savostyanov ${ }^{2}$
}

Received: 17 April 2017 /Revised: 3 August 2017 / Accepted: 4 August 2017 / Published online: 4 September 2017

(C) The Author(s) 2017. This article is an open access publication

\begin{abstract}
Our objective was to examine the prevalence of Fabry disease in Russian children with chronic pain in the distal limbs. This non-interventional, multi-centre study included children 2-18 years of age with chronic recurrent unilateral or bilateral pain, burning, or acroparesthesia in the hands or feet. The presence of Fabry disease was defined by abnormal alpha-galactosidase A activity in males or alphagalactosidase gene (GLA) mutation in females. Among 214 patients (110 males), $84.1 \%$ had bilateral limb pain and $31.8 \%$ had unilateral limb pain recorded at some time point; 61 $(28.5 \%)$ patients had a positive family history possibly associated with Fabry disease. Alpha-galactosidase A activity was within the normal range in all 109 of the male patients tested. One female patient had a GLA mutation $(\mathrm{C} 937 \mathrm{G}>\mathrm{T})$ and alpha-galactosidase $\mathrm{A}$ activity within the normal range.
\end{abstract}

Communicated by Peter de Winter

Leyla Seymurovna Namazova-Baranova

namazova@nczd.ru

Alexander Alexandrovich Baranov

baranov@nczd.ru

Aleksander Alekseevich Pushkov

pushkovgenetika@gmail.com

Kirill Victorovich Savostyanov

7443333@gmail.com

1 Institute of Paediatrics, Federal State Autonomous Institution "National Medical Research Center of Children's Health" of the Ministry of Health of the Russian Federation, Lomonosovsky prospekt, 2, b.1, 119991 Moscow, Russia

2 Laboratory of Molecular Genetics and Cell Biology, Federal State Autonomous Institution "Scientific Center of Children's Health" of the Ministry of Health of the Russian Federation, Moscow, Russia
Conclusion: We did not find definitive evidence of Fabry disease in these children with a history of chronic recurrent unilateral or bilateral limb pain or acroparesthesia. The presence of chronic limb pain does not appear to be highly predictive of a diagnosis of Fabry disease in Russian children and adolescents, suggesting that key early signs and symptoms of Fabry disease are not specific to the disease.

What is Known:

- Signs and symptoms of Fabry disease are seen in children $<10$ years of age; pain in the distal limbs is a common early symptom.

What is New:

- Fabry disease was not diagnosed in this population of Russian children with a history of chronic limb pain.

- The presence of acroparesthesia or chronic limb pain does not appear to be highly predictive of a diagnosis of Fabry disease in Russian children and adolescents, suggesting that these early symptoms of Fabry disease are not specific to the disease.

Keywords Acroparesthesia - Alpha-galactosidase A . Children $\cdot$ Fabry disease $\cdot$ Limb pain $\cdot$ Screening
Abbreviations
GLA alpha-galactosidase gene
SD standard deviation

\section{Introduction}

Fabry disease (OMIM 301500) is an X-linked lysosomal storage disease associated with a functional deficiency of the lysosomal enzyme alpha-galactosidase A that results in substantial morbidity and premature mortality $[16,17,26,28]$. Signs 
and symptoms of Fabry disease can occur in children of both sexes under 10 years of age [26-28].

Classic Fabry disease is seen in hemizygous males with minimal functional alpha-galactosidase A activity. Affected males display the classic phenotype, with the development of characteristic signs and symptoms, including angiokeratomas, acroparesthesia, and hypohydrosis, beginning in childhood and followed by progressive renal, cardiac, and cerebrovascular disease as globotriaosylceramide accumulates in lysosomes throughout the body [4]. Impaired inflammatory and immune responses have been implicated as contributing to disease progression [2, 38].

Other forms of Fabry disease include asymptomatic to severe disease in heterozygous females and later-onset phenotypes associated with renal, cardiac, and cerebrovascular complications in males with various non-classic mutations [4].

Previous reports have estimated the overall frequency of Fabry disease to range between 1 per 117,000 total births [20] and $\sim 1$ in 40,000 males [4]. Early diagnosis of Fabry disease is often difficult, especially in females, because the symptoms are variable and non-specific [10, 23, 35]. Pain in the distal extremities is a common symptom of Fabry disease, starting in early childhood [37]. Screening for chronic pain in the paediatric population has not previously been explored as a means of identifying patients with Fabry disease.

The primary objective of this study was to assess the prevalence of Fabry disease in an enriched population of paediatric patients with chronic limb pain. A secondary objective was to determine the success rate of study definitions in diagnosing Fabry disease in this population.

\section{Materials and methods}

\section{Study design and patient population}

This was a non-interventional, multi-centre study conducted from December 2013 to March 2015 in seven regions of the Russian Federation with a total population of approximately 38 million: Moscow City, Moscow Region, Saint Petersburg City, Saratov Region, Samara Region, Rostov Region, and Sverdlovsk Regions [30].

Eligible patients were boys and girls 2-18 years of age who presented to a paediatric specialty clinic with a history of chronic ( $\geq 6$ months) recurrent unilateral or bilateral pain, burning, or acroparesthesia in the hands or feet and were considered by the screening physician to be suitable for laboratory testing based on the presence or medical history of additional Fabry disease indicators. These indicators were categorised into three groups and blood sampling was indicated for patients with a single group 1 or group 2 criterion or two group 3 criteria (Table 1). A positive family history was defined as either a family history of Fabry disease or a first-degree relative with a history of renal failure, stroke, or enlarged heart of unknown aetiology.

The study endpoint was the presence or absence of Fabry disease, which was defined as abnormal alpha-galactosidase A activity in males or an alpha-galactosidase gene (GLA) mutation in females.

\section{Laboratory testing}

Blood samples were drawn to analyse alpha-galactosidase A activity and GLA mutations. Alpha-galactosidase A activity was measured in dried blood spots using ultra-performance liquid chromatography-tandem mass spectrometry. Reference values for alpha-galactosidase in our laboratory were determined experimentally and validated according to established protocols.

\section{Statistical analysis}

Descriptive statistics were calculated to evaluate the overall prevalent patient population. A two-tailed Student's $t$ test was used to compare males with females and to compare children ( $<14$ years of age) with adolescents $(\geq 14$ years of age).

The prevalence of Fabry disease was estimated by calculating the $F D-R$ coefficient:

$F D-R=[F D] /[D]$

where $[F D]$ is the number of patients with diagnosed Fabry disease and $[D]$ is the number of patients who met the inclusion criteria and were selected for analysis of alphagalactosidase A activity and/or GLA mutations.

Furthermore, the efficacy of the screening method proposed for detecting patients with Fabry disease was estimated by calculating the $E f$ coefficient:

$E f=[F D] /[C]$

where $[F D]$ is the number of patients with diagnosed Fabry disease and $[C]$ is the number of patients $2-18$ years of age who reported to a specialty clinic with pain as the chief complaint and with chronic ( $\geq 6$ months) unilateral or bilateral pain, burning, or acroparesthesia of unknown cause in the hands or feet.

\section{Results}

\section{Patients and demographic characteristics}

A total of 214 patients (110 males and 104 females) fulfilled the inclusion criteria and were selected for screening. Of these, $84.1 \%$ had bilateral limb pain recorded at some point and 
Table 1 Fabry disease indicators for laboratory testing

One criterion from group 1 or 2 :

Group $1 \quad$ Group 2

- Positive family history of Fabry disease

- Skin angiokeratomas

- First-degree relative with history of renal failure, stroke or enlarged heart of unknown aetiology

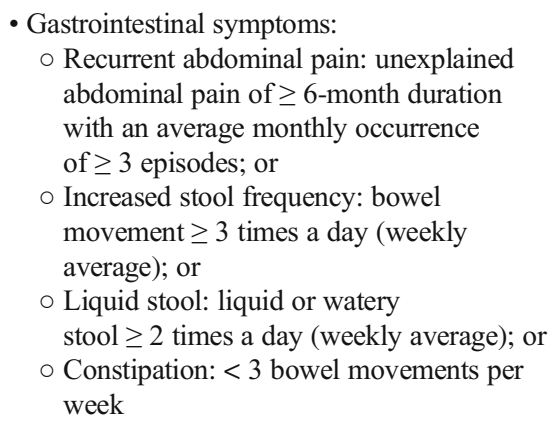
abdominal pain of $\geq 6$-month duration with an average monthly occurrence of $\geq 3$ episodes; or

- Increased stool frequency: bowel movement $\geq 3$ times a day (weekly average); or

- Liquid stool: liquid or watery stool $\geq 2$ times a day (weekly average); or

o Constipation: $<3$ bowel movements per week

Or two criteria from:

Group 3

- Heat/cold intolerance: positive answer to "Does cold and/or hot weather cause an increase in limb pain or a decrease in the ability to engage in outdoor activities?"

- Exercise intolerance: positive answer to "Is your child limited in the amount of physical activity he/she can do compared to other children?"

- Decreased sweating: negative answer to one of the following

○ "When it is hot outside, does your child sweat while doing activities?" or

o "If your child does sweat, do you think he/she is sweating enough?"
$31.8 \%$ had unilateral limb pain recorded at some point. No statistically significant differences were observed in age or ethnicity between males and females (Table 2).

\section{Signs and symptoms of Fabry disease}

The prevalence in females and males of chronic recurrent unilateral and bilateral limb pain/acroparesthesia is shown in Table 2; prevalence by location is shown in Fig. 1. Recurrent unilateral limb pain/acroparesthesia was reported less frequently in children $(38.0 \%)$ than in adolescents $(61.1 \% ; p=0.014$; Fig. 2).
The mean (standard deviation [SD]) intensity of limb pain on a 10-point scale was 5.1 (1.7) in the overall population. Mean [SD] intensity of limb pain was significantly higher in females $(5.3[1.7])$ than in males $(5.0[1.6] ; p=0.024)$ and was significantly higher in adolescents $(5.5[1.4])$ than in children (5.0 [1.7]; $p=0.041)$.

As a whole, general gastrointestinal disorders or recurrent abdominal pain were observed in $75.0 \%$ of girls and $66.4 \%$ of boys ( $p=0.17$; Table 2). Recurrent abdominal pain of unknown origin was seen in approximately $48 \%$ of the patients overall (Table 2), and the prevalence was not significantly different between females and males $(p=0.40)$. The
Table 2 Demographic and clinical characteristics

\begin{tabular}{llll}
\hline Characteristic & $\begin{array}{l}\text { Female } \\
n=104\end{array}$ & $\begin{array}{l}\text { Male } \\
n=110\end{array}$ & $\begin{array}{l}\text { Overall } \\
N=214\end{array}$ \\
\hline Age, median (range) years & $10.4(2.1-17.9)$ & $10.6(2.2-17.9)$ & $10.6(2.1-17.9)$ \\
$\quad$ Age group $<14$ years, $n(\%)$ & $79(47.6)$ & $87(52.4)$ & $166(100)$ \\
$\quad$ Age group $\geq 14$ years, $n(\%)$ & $19(39.6)$ & $29(60.4)$ & $48(100)$ \\
Caucasian, $n(\%)$ & $102(98.1)$ & $106(96.4)$ & $208(97.2)$ \\
Recurrent unilateral limb pain/acroparesthesia, $n(\%)^{\mathrm{a}}$ & $38(46.3)$ & $30(40.0)$ & $68(43.3)$ \\
& $n=82$ & $n=75$ & $n=157$ \\
Recurrent bilateral limb pain/acroparesthesia, $n(\%)^{\mathrm{a}}$ & $88(85.4)$ & $92(86.0)$ & $180(85.7)$ \\
& $n=103$ & $n=107$ & $n=210$ \\
General gastrointestinal disorders or recurrent & $78(75.0)$ & $73(66.4)$ & $151(70.6)$ \\
$\quad$ abdominal pain, $n(\%)$ & $48(46.2)$ & $55(50.0)$ & $103(48.1)$ \\
Recurrent abdominal pain of unknown origin, $n(\%)$ & $11(10.6)$ & $10(9.1)$ & $21(9.8)$ \\
Angiokeratomas, $n(\%)$ & $40(38.5)$ & $57(51.8)$ & $97(45.3)$ \\
Heat and/or cold intolerance, $n(\%)$ & $72(69.2)$ & $73(66.4)$ & $145(67.8)$ \\
Exercise intolerance, $n(\%)$ & $29(27.9)$ & $40(36.4)$ & $69(32.2)$ \\
Anhydrosis or hypohydrosis & & & \\
\hline
\end{tabular}

${ }^{\text {a }}$ Percentages based on number of patients with available data 
a Unilateral limb pain

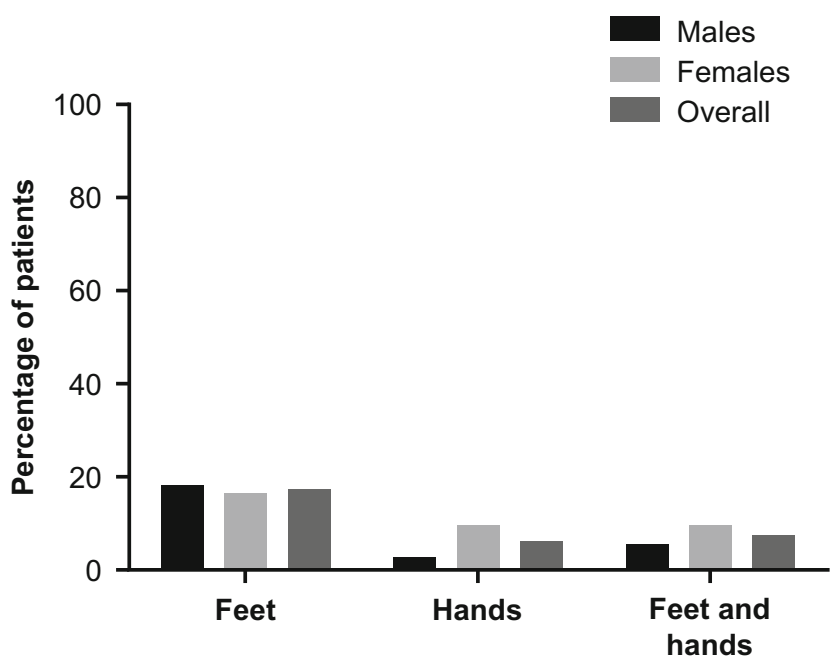

b Bilateral limb pain

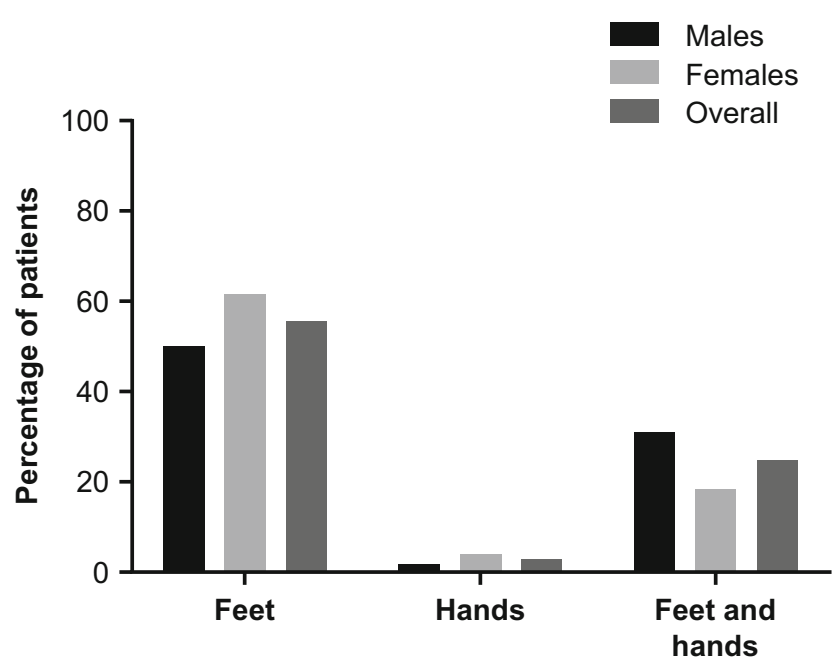

Fig. 1 Recurrent limb pain/acroparesthesia by location. a Unilateral. b Bilateral

prevalence of various signs and symptoms commonly associated with Fabry disease is shown in Table 2.

\section{Family history}

Overall, $61(28.5 \%)$ patients had a positive family history possibly associated with Fabry disease. None of the patients had an immediate relative with a diagnosis of Fabry disease. There were six $(2.8 \%)$ patients (three females, three males) who had relatives with current renal failure, and one $(0.5 \%)$ patient had a relative who died from renal failure. A total of 45 $(21.0 \%)$ patients ( 27 females, 18 males) had relatives with premature cardiovascular disease $(<50$ years of age), and 22 $(10.3 \%)$ had a relative who died from cardiovascular disease younger than 50 years of age.

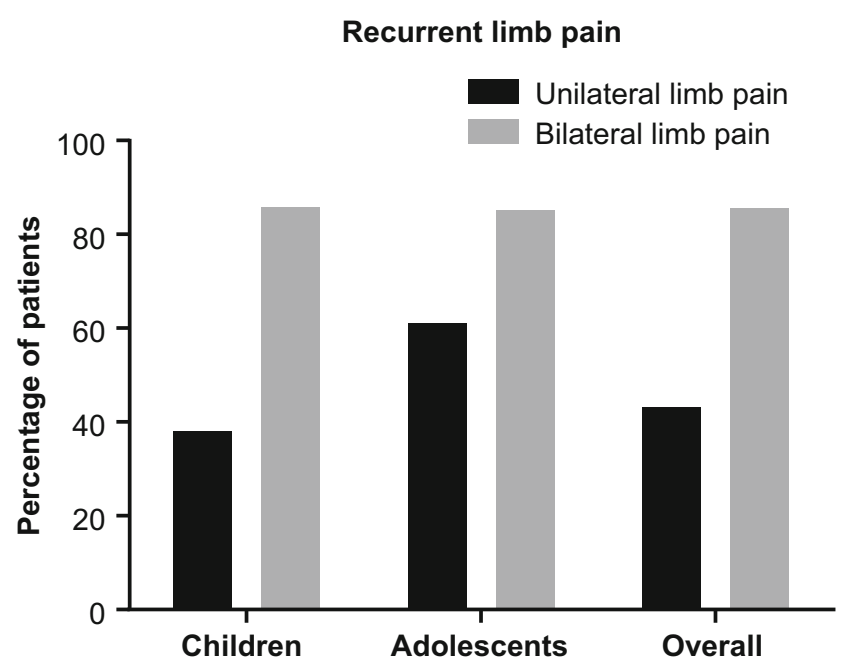

Fig. 2 Recurrent unilateral and bilateral limb pain/acroparesthesia by age group

\section{Laboratory testing}

Alpha-galactosidase A activity (Table 3) was within the normal range in all 109 of the male patients tested. A mutation of GLA (C937G > T) was detected in only one of the 104 female patients tested. This patient had bilateral daily pain in her feet for $>10$ years, exercise intolerance, heat/cold intolerance, and anhydrosis. Her alpha-galactosidase A activity was considered to be within the normal range (the specific value was not available).

\section{Integral study results}

The coefficient $F D$ - $R$, to characterise the prevalence of Fabry disease, was calculated as $1 / 261 \approx 0.0038$. This is equivalent to 38 patients with Fabry disease per 10,000 patients in the enriched population of paediatric patients with chronic limb pain.

The coefficient $E f$, to characterise the efficacy of the screening method used for the detection of patients with Fabry disease, was calculated as $1 / 1736 \approx 0.00058$. This is equivalent to 58 patients with Fabry disease per 100,000 patients with chronic pain, burning, or acroparesthesia of unknown aetiology in the hands or feet.

Table 3 Blood testing for alpha-galactosidase A activity in males

\begin{tabular}{ll}
\hline $\begin{array}{l}\text { Alpha-galactosidase } \mathrm{A}, \\
\mu \mathrm{mol} / \mathrm{L} / \mathrm{h}\end{array}$ & $n=109$ \\
\hline Minimum & 2.38 \\
Maximum & 25.08 \\
Median & 4.62 \\
Mean & 5.93 \\
Standard deviation & 3.80 \\
\hline
\end{tabular}




\section{Discussion}

We did not find definitive evidence of Fabry disease in this enriched population of Russian children with a history of chronic recurrent unilateral or bilateral limb pain or acroparesthesia. Gastrointestinal disorders, angiokeratomas, heat and/or cold intolerance, and anhydrosis or hypohydrosis, all commonly reported features of classic Fabry disease, occurred at frequencies varying from 9.8 to $75 \%$ overall. This may indicate that such features are not specific to Fabry disease when aligned with chronic recurrent limb pain or acroparesthesia. Gastrointestinal disorders, in particular, are non-specific symptoms that are particularly prevalent in the general paediatric population. This is reflected in our study, with gastrointestinal symptoms reported in $\sim 70 \%$ of children.

The non-pathogenic GLA mutation $\mathrm{C} 937 \mathrm{G}>\mathrm{T}$ was detected in only one symptomatic girl with normal alphagalactosidase A activity. This is classified as a "pseudodeficiency" mutation and has been described in individuals with normal or somewhat decreased alphagalactosidase A activity without other evidence of Fabry disease [7, 8]. Diagnosis of Fabry disease is especially difficult in females, as enzyme levels alone are generally not sufficient and genetic analysis is normally required $[10,35]$.

Screening studies for Fabry disease have previously been reported in other subpopulations. For example, in a study of patients with small-fibre neuropathy, 5/24 (20.8\%) were found to have GLA mutations [34]. In patients with left ventricular hypertrophy, the prevalence of Fabry disease has been variously reported between 0.5 and $11.8 \%$ [1, 6, 15]. In young adult patients with stroke, Fabry disease prevalence has been reported to be between 0.3 and $2.8 \%$ overall $[9,29,36]$, and to be $4.2 \%$ in men and $2.1 \%$ in women [15]. Atypical variants of Fabry disease associated with renal involvement may be diagnosed, and functional variants of GLA may be present in patients with end-stage renal disease [5, 13, 14, 21]. Furthermore, the prevalence of Fabry disease among dialysis patients has been variously reported as 0.33 to $3.2 \%$ in men, $0.10 \%$ in women [15, 18], and 0.02 to $0.32 \%$ overall $[21,22,31]$.

The incidence of Fabry disease in the general population has been estimated as about 1 in 40,000 males [4]. Studies from different countries report varying frequencies of Fabry disease. Based on data from the Netherlands during the period 1970 to 1996 (covering birth years 1926 to 1986), the prevalence was estimated to be 0.42 per 100,000 (or $~ 1$ per $238,100)$ male births [25]. Fabry disease prevalence was estimated to be $\sim 1$ per 117,000 births during the period 1980 through 1996 [20] in Australia and to be 0.12 per 100,000 (or $\sim 1$ per 833,000) live births in northern Portugal [24]. In a UK study, the prevalence among male individuals was estimated to be $\sim 1$ in 366,000 [16].

Screening of 37,104 consecutive newborn males in Italy found that $\sim 1$ in 3100 males had Fabry disease based on abnormally low alpha-galactosidase A activity levels and the presence of alpha-galactosidase A mutations [33]. The same study estimated the prevalence of classic Fabry disease as $\sim 1$ in 37,000 newborn males in Italy [33]. In Taiwan, enzymebased screening of 171,977 infants at 3 days of age indicated an overall frequency of $\sim 1$ in 1250 males and $\sim 1$ in 40,840 females [11], and classic Fabry disease was estimated to occur in about 1 in 22,570 newborn males [11]. In other studies, the screening of 21,170 newborn infants in Japan showed a prevalence of 1 in 7057 [12]; laboratory screening of $\sim 54,800$ newborn males in the US state of WA revealed a prevalence of $\sim 1$ in 7800 [32]; and screening of 34,736 consecutive newborn infants in Austria found mutations characteristic of Fabry disease in 1 per 3859 births [19].

The prevalence of non-classic or later-onset Fabry disease has also been investigated. For example, the prevalence of carriers was estimated to be $\sim 1$ in 339,000 females in the UK [17]. In a screening study of newborn males in Italy, $\sim 1$ in 3100 to 4600 was identified with a later-onset phenotype, giving a ratio of approximately 7:1 of patients with a later-onset:classic phenotype [33]. In Taiwan, the estimated frequency of the later-onset phenotype was $\sim 1$ in 1390 newborn males; for the IVS4 mutation it was $\sim 1$ in 1460 newborn males on the basis of enzyme-based screening [11]. Subsequent DNA-based screening in 20,063 newborn males and females found the prevalence of the IVS4 mutation to be $\sim 1$ in 875 males and $\sim 1$ in 399 females [3].

This is the first analysis of Fabry disease prevalence in an enriched population of paediatric patients with chronic limb pain. Patient numbers were relatively low, although this is to be expected in rare disease studies. Fabry disease was not diagnosed in this population of Russian children with a history of chronic limb pain. The presence of acroparesthesia or chronic limb pain does not appear to be highly predictive of a diagnosis of Fabry disease in Russian children and adolescents, even after applying a Fabry disease-specific enrichment protocol, raising the question of the specificity of these indicators and suggesting that key early signs and symptoms of Fabry disease are not specific to the disease. Future studies, including the detection of polymorphisms and pathogenic variants in GLA, will permit analysis of genotype-phenotype correlations and should allow us to apply a personalised approach to the management of these patients in the future; these may also allow the identification of other biomarkers and the creation of a diagnostic algorithm based on a mathematical model of various indicators suggesting a differential diagnosis of Fabry disease.

Acknowledgements This research was funded by the sponsor, Shire International $\mathrm{GmbH}$. The sponsor was involved in the study design and in collection and analysis of the data but had no role in the interpretation of data, the writing of the report, or the decision to submit the manuscript for publication. Under the direction of the authors, Margit Rezabek, DVM, PhD, employee of Excel Scientific Solutions, provided writing 
assistance for this publication. Editorial assistance in formatting, proofreading, copy-editing, and fact-checking was also provided by Excel Scientific Solutions. Andrey Gurevich, MD, PhD and Ekaterina Musaeva, $\mathrm{MD}, \mathrm{PhD}$ from Shire International $\mathrm{GmbH}$ also reviewed and edited the manuscript for scientific accuracy. Shire International GmbH provided funding to Excel Scientific Solutions for support in writing and editing this manuscript.

Authors' contributions All the authors made substantial contributions to the conception and design, the acquisition of data, and the analysis and interpretation of data. All the authors were involved in revising the manuscript critically for important intellectual content and gave final approval of the version to be published. Each author has participated sufficiently in the work to take public responsibility for appropriate portions of the content and agrees to be accountable for all aspects of the work in ensuring that questions related to the accuracy or integrity of any part of the work are appropriately investigated and resolved.

Compliance with ethical standards The protocol was registered with the Federal State Research Institution "Centre of Informational Technologies and Systems of Executive Bodies" of the Ministry of Education and Science of the Russian Federation (registration number 01201376879). Written informed consent or assent was obtained and documented for each patient before study participation, and the ethical conduct of the study complied with the principles of Russian legislation, the International Council for Harmonisation and European Good Clinical Practice Guidelines, and the Declaration of Helsinki.

Conflict of interest The authors declare that they have no competing interests.

Open Access This article is distributed under the terms of the Creative Commons Attribution 4.0 International License (http:// creativecommons.org/licenses/by/4.0/), which permits unrestricted use, distribution, and reproduction in any medium, provided you give appropriate credit to the original author(s) and the source, provide a link to the Creative Commons license, and indicate if changes were made.

\section{References}

1. Baptista A, Magalhães P, Leão S, Carvalho S, Mateus P, Moreira I (2015) Screening for Fabry disease in left ventricular hypertrophy: documentation of a novel mutation. Arq Bras Cardiol 105:139-144

2. Biancini GB, Vanzin CS, Rodrigues DB, Deon M, Ribas GS, Barschak AG, Manfredini V, Netto CB, Jardim LB, Giugliani R et al (2012) Globotriaosylceramide is correlated with oxidative stress and inflammation in Fabry patients treated with enzyme replacement therapy. Biochim Biophys Acta 1822:226-232

3. Chien YH, Lee NC, Chiang SC, Desnick RJ, Hwu WL (2012) Fabry disease: incidence of the common later-onset alpha-galactosidase A IVS4+919G $\rightarrow$ A mutation in Taiwanese newborns- - superiority of DNA-based to enzyme-based newborn screening for common mutations. Mol Med 18:780-784

4. Desnick RJ, Ioannou YA, Eng CM (2001) $\alpha$-Galactosidase A deficiency: Fabry disease. In: Scriver CR, Beaudet AL, Sly WS, Valle D, Kinzler KE, Vogelstein B (eds) The metabolic and molecular bases of inherited disease. McGraw-Hill, New York, pp 3733-3774

5. Doi K, Noiri E, Ishizu T, Negishi K, Suzuki Y, Hamasaki Y, Honda K, Fujita T, Tsukimura T, Togawa T et al (2012) High-throughput screening identified disease-causing mutants and functional variants of alpha-galactosidase A gene in Japanese male hemodialysis patients. J Hum Genet 57:575-579

6. Elliott P, Baker R, Pasquale F, Quarta G, Ebrahim H, Mehta AB, Hughes DA (2011) Prevalence of Anderson-Fabry disease in patients with hypertrophic cardiomyopathy: the European AndersonFabry Disease Survey. Heart 97:1957-1960

7. Froissart R, Guffon N, Vanier MT, Desnick RJ, Maire I (2003) Fabry disease: D313Y is an alpha-galactosidase A sequence variant that causes pseudodeficient activity in plasma. Mol Genet Metab 80:307-314

8. Gal A, Hughes DA, Winchester B (2011) Toward a consensus in the laboratory diagnostics of Fabry disease - recommendations of a European expert group. J Inherit Metab Dis 34:509-514

9. Goeggel Simonetti B, Mono ML, Huynh-Do U, Michel P, Odier C, Sztajzel R, Lyrer P, Engelter ST, Bonati L, Gensicke H et al (2015) Risk factors, aetiology and outcome of ischaemic stroke in young adults: the Swiss Young Stroke Study (SYSS). J Neurol 262:20252032

10. Hoffmann B, Mayatepek E (2009) Fabry disease — often seen, rarely diagnosed. Dtsch Arztebl Int 106:440-447

11. Hwu WL, Chien YH, Lee NC, Chiang SC, Dobrovolny R, Huang AC, Yeh HY, Chao MC, Lin SJ, Kitagawa T et al (2009) Newborn screening for Fabry disease in Taiwan reveals a high incidence of the later-onset GLA mutation c.936+919G > A (IVS4+919G > A). Hum Mutat 30:1397-1405

12. Inoue T, Hattori K, Ihara K, Ishii A, Nakamura K, Hirose S (2013) Newborn screening for Fabry disease in Japan: prevalence and genotypes of Fabry disease in a pilot study. J Hum Genet 58:548-552

13. Kikumoto Y, Sugiyama H, Morinaga H, Inoue T, Takiue K, Kitagawa M, Saito D, Takatori Y, Kinomura M, Kitamura S et al (2012) The frequency of Fabry disease with the E66Q variant in the alpha-galactosidase A gene in Japanese dialysis patients: a case report and a literature review. Clin Nephrol 78:224-229

14. Kusano E, Saito O, Akimoto T, Asano Y (2014) Fabry disease: experience of screening dialysis patients for Fabry disease. Clin Exp Nephrol 18:269-273

15. Linthorst GE, Bouwman MG, Wijburg FA, Aerts JM, Poorthuis BJ, Hollak CE (2010) Screening for Fabry disease in high-risk populations: a systematic review. J Med Genet 47:217-222

16. MacDermot KD, Holmes A, Miners AH (2001) Anderson-Fabry disease: clinical manifestations and impact of disease in a cohort of 98 hemizygous males. J Med Genet 38:750-760

17. MacDermot KD, Holmes A, Miners AH (2001) Anderson-Fabry disease: clinical manifestations and impact of disease in a cohort of 60 obligate carrier females. J Med Genet 38:769-775

18. Maruyama H, Takata T, Tsubata Y, Tazawa R, Goto K, Tohyama J, Narita I, Yoshioka H, Ishii S (2013) Screening of male dialysis patients for Fabry disease by plasma globotriaosylsphingosine. Clin J Am Soc Nephrol 8:629-636

19. Mechtler TP, Stary S, Metz TF, De Jesús VR, Greber-Platzer S, Pollak A, Herkner KR, Streubel B, Kasper DC (2012) Neonatal screening for lysosomal storage disorders: feasibility and incidence from a nationwide study in Austria. Lancet 379:335-341

20. Meikle PJ, Hopwood JJ, Clague AE, Carey WF (1999) Prevalence of lysosomal storage disorders. JAMA 281:249-254

21. Nishino T, Obata Y, Furusu A, Hirose M, Shinzato K, Hattori K, Nakamura K, Matsumoto T, Endo F, Kohno S (2012) Identification of a novel mutation and prevalence study for Fabry disease in Japanese dialysis patients. Ren Fail 34:566-570

22. Okur I, Ezgu F, Biberoglu G, Tumer L, Erten Y, Isitman M, Eminoglu FT, Hasanoglu A (2013) Screening for Fabry disease in patients undergoing dialysis for chronic renal failure in Turkey: identification of new case with novel mutation. Gene 527:42-47

23. Park KB, Han KR, Lee JW, Kim SH, Kim DW, Kim C, Ko JM (2010) Early diagnosis of Fabry disease in a patient with toe tip pain. Korean J Pain 23:207-210 
24. Pinto R, Caseiro C, Lemos M, Lopes L, Fontes A, Ribeiro H, Pinto E, Silva E, Rocha S, Marcão A et al (2004) Prevalence of lysosomal storage diseases in Portugal. Eur J Hum Genet 12:87-92

25. Poorthuis BJ, Wevers RA, Kleijer WJ, Groener JE, de Jong JG, van Weely S, Niezen-Koning KE, van Diggelen OP (1999) The frequency of lysosomal storage diseases in The Netherlands. Hum Genet 105:151-156

26. Ramaswami U, Whybra C, Parini R, Pintos-Morell G, Mehta A, Sunder-Plassmann G, Widmer U, Beck M (2006) Clinical manifestations of Fabry disease in children: data from the Fabry Outcome Survey. Acta Paediatr 95:86-92

27. Ries M, Ramaswami U, Parini R, Lindblad B, Whybra C, Willers I, Gal A, Beck M (2003) The early clinical phenotype of Fabry disease: a study on 35 European children and adolescents. Eur J Pediatr 162:767-772

28. Ries M, Gupta S, Moore DF, Sachdev V, Quirk JM, Murray GJ, Rosing DR, Robinson C, Schaefer E, Gal A et al (2005) Pediatric Fabry disease. Pediatrics 115:e344-e355

29. Romani I, Borsini W, Nencini P, Morrone A, Ferri L, Frusconi S, Donadio VA, Liguori R, Donati MA, Falconi S et al (2015) De novo diagnosis of Fabry disease among Italian adults with acute ischemic stroke or transient ischemic attack. J Stroke Cerebrovasc Dis 24: $2588-2595$

30. Russian Federal State Statistics Service (2015) Provisional population estimates on average in:2014 http://www.gks.ru/free_doc/ new_site/population/demo/prPopul2015.xls. Accessed 9 February 2016
31. Saito O, Kusano E, Akimoto T, Asano Y, Kitagawa T, Suzuki K, Ishige N, Akiba T, Saito A, Ishimura E et al (2016) Prevalence of Fabry disease in dialysis patients: Japan Fabry disease screening study (J-FAST). Clin Exp Nephrol 20:284-293

32. Scott CR, Elliott S, Buroker N, Thomas LI, Keutzer J, Glass M, Gelb MH, Turecek F (2013) Identification of infants at risk for developing Fabry, Pompe, or mucopolysaccharidosis-I from newborn blood spots by tandem mass spectrometry. J Pediatr 163:498503

33. Spada M, Pagliardini S, Yasuda M, Tukel T, Thiagarajan G, Sakuraba H, Ponzone A, Desnick RJ (2006) High incidence of later-onset Fabry disease revealed by newborn screening. Am J Hum Genet 79:31-40

34. Tanislav C, Kaps M, Rolfs A, Böttcher T, Lackner K, Paschke E, Mascher H, Laue M, Blaes F (2011) Frequency of Fabry disease in patients with small-fibre neuropathy of unknown aetiology: a pilot study. Eur J Neurol 18:631-636

35. Thomas AS, Mehta AB (2013) Difficulties and barriers in diagnosing Fabry disease: what can be learnt from the literature? Expert Opin Med Diagn 7:589-599

36. Tuttolomondo A, Pecoraro R, Simonetta I, Miceli S, Arnao V, Licata G, Pinto A (2013) Neurological complications of Anderson-Fabry disease. Curr Pharm Des 19:6014-6030

37. Üçeyler N, Ganendiran S, Kramer D, Sommer C (2014) Characterization of pain in Fabry disease. Clin J Pain 30:915-920

38. Vitner EB, Platt FM, Futerman AH (2010) Common and uncommon pathogenic cascades in lysosomal storage diseases. J Biol Chem 285:20423-20427 